\title{
Future Changes in Surface Runoff over Korea Projected by a Regional Climate Model under A1B Scenario
}

\author{
Ji-Woo Lee, ${ }^{1}$ Suryun Ham, ${ }^{2}$ Song-You Hong, ${ }^{3}$ Kei Yoshimura, ${ }^{2}$ and Minsu Joh ${ }^{1}$ \\ ${ }^{1}$ Supercomputing Service Center, Korea Institute of Science and Technology Information, \\ 245 Daehak-ro, Yuseong-gu, Daejeon 305-806, Republic of Korea \\ ${ }^{2}$ Atmosphere and Ocean Research Institute, The University of Tokyo, Kashiwa, Chiba, Japan \\ ${ }^{3}$ Korea Institute of Atmospheric Prediction System, Seoul, Republic of Korea \\ Correspondence should be addressed to Minsu Joh; msjoh@kisti.re.kr
}

Received 3 July 2014; Revised 2 September 2014; Accepted 4 September 2014; Published 21 September 2014

Academic Editor: Eduardo García-Ortega

Copyright (C) 2014 Ji-Woo Lee et al. This is an open access article distributed under the Creative Commons Attribution License, which permits unrestricted use, distribution, and reproduction in any medium, provided the original work is properly cited.

This study assesses future change of surface runoff due to climate change over Korea using a regional climate model (RCM), namely, the Global/Regional Integrated Model System (GRIMs), Regional Model Program (RMP). The RMP is forced by future climate scenario, namely, A1B of Intergovernmental Panel on Climate Change (IPCC) Fourth Assessment Report (AR4). The RMP satisfactorily reproduces the observed seasonal mean and variation of surface runoff for the current climate simulation. The distribution of monsoonal precipitation-related runoff is adequately captured by the RMP. In the future (2040-2070) simulation, it is shown that the increasing trend of temperature has significant impacts on the intra-annual runoff variation. The variability of runoff is increased in summer; moreover, the strengthened possibility of extreme occurrence is detected in the future climate. This study indicates that future climate projection, including surface runoff and its variability over Korea, can be adequately addressed on the RMP testbed. Furthermore, this study reflects that global warming affects local hydrological cycle by changing major water budget components. This study adduces that the importance of runoff should not be overlooked in regional climate studies, and more elaborate presentation of fresh-water cycle is needed to close hydrological circulation in RCMs.

\section{Introduction}

The surface runoff is one of the major components of the terrestrial hydrological cycle along with the precipitation and evaporation, which affects human activities by determining the water supply. Since the hydrological cycle is responsive to the climate change [1], the consequent impacts on surface runoff contribute to various social problems related to changes in the availability or absence of water, for example, flooding or drought (e.g., $[2,3])$. For the formulation of regional policies on preventing possible water resource problems, predictions of the future surface runoff conditions and their variability are preferentially required.

One of widely used methods for assessing the impacts of future climate change on surface runoff is employing global climate models (GCMs) with climate change projection scenarios [4]. There are three different kinds of approaching method to the surface runoff from the GCM results: (1) using direct output of GCM which includes a land surface model (LSM) or simple water budget (e.g., [5-7]), (2) adapting hydrological single column model, which calculates surface and subsurface water budget, for statistically downscaled GCM data (e.g., [8-10]), and (3) dynamical downscaling with a nested regional climate model (RCM) for target area such as a river basin (e.g., $[11,12])$.

The GCM is a valuable tool for future climate prediction; however, its coarse spatial resolution (generally $>100 \mathrm{~km}$ ) restricts adequate representation of anomalous surface forcing. The direct output of GCM is insufficient to represent regional scale hydrological cycle. The abovementioned second and third methods are excogitated to overcome such limitation of GCM. It is arguable which one shows higher reproducibility of regional climatology; however, the statistical downscaling could be improper for future climate simulations because of inflexible empirical relationship between GCM-simulated circulation and local features, which is hard 
to be adapted to the future climate if there is a significant alteration of circulation [13]. This erroneous result penetrates to the hydrological single column model, declining the predictability of hydrological features. On the contrary, the dynamical downscaling method is likely to respond to the changing large-scale climate even in the future simulation since it explicitly represents mesoscale processes and terrain influences by the RCM (e.g., [14-17]).

As computational growth covers expensive computation of the RCMs which was a weak point of the dynamical downscaling, RCMs have been intensively adapted to studies regarding climate change impacts on surface runoff. For instance, Kjellström and Lind [12] investigated changes of water budget in Northern Europe using Rossby Centre regional atmospheric climate model forced by GCM which follows Intergovernmental Panel on Climate Change (IPCC) Fourth Assessment Report (AR4) scenarios and showed that the hydrological cycle in that region will likely become more intense in the future. Sanchez-Gomez et al. [11] studied changes in the Mediterranean water budget using multimodel ensemble of RCMs with a GCM of IPCC AR4 scenario run. They predicted progressive drying of the Mediterranean region which consequently increases the salinity of the Mediterranean. Shi et al. [18] assessed future change of hydrological budget over Tibetan Plateau using RegCM3 model. These studies denoted that RCMs provide credible representation of current surface runoff and are capable of appraising its future change.

In this study, a transition of surface runoff by future climate change over Asia and Korea is investigated using a RCM. We perform dynamical downscaling by the Regional Model Program (RMP) of the Global/Regional Integrated Model System (GRIMs; [19]) with the European Centre Hamburg Version 5 (ECHAM5; [20]) as a large-scale forcing. Experiments are conducted for the current (1980-2000) and future (2040-2070) climate. As a prerequisite for future climate change assessment, the RMP's ability is evaluated to provide regional scale details embedded within a low-resolution global model, and consequently, the future climatology is compared to the current climatology. This paper is organized as follows. The model description and experimental setup are given in Section 2. Section 3 provides evaluations of the downscaled results from the RMP for the current climate. A comparison of future and current climates is presented in Section 4. Finally, summary and conclusions appear in Section 5 .

\section{Model and Experimental Setup}

2.1. Regional Climate Model. In this study, the GRIMs-RMP (hereafter RMP) is applied as a RCM. The spectral representation of the RMP is a two-dimensional cosine series for perturbations of pressure, divergence, temperature, and mixing ratio but a two-dimensional sine series for the perturbation of vorticity. Linear computations of horizontal diffusion and semi-implicit adjustment are only considered as perturbations, and thus the error due to the reevaluation of the linear forcing from the base fields is eliminated [21, 22]. The physics package of the RMP employs the Simplified ArakawaSchubert (SAS) convection scheme [23] for convective parameterization, a diagnostic microphysics scheme [24], the Yonsei University planetary boundary layer (YSUPBL) scheme [25], the National Centers for Environmental Prediction (NCEP)-Oregon State University-US Air ForceNational Weather Service Office of Hydrologic Development (NOAH) land surface model (LSM) [26, 27], and the shortwave [28] and long-wave [29] radiation parameterizations. To prevent the distortion of large-scale fields, the revised Scale Selective Bias Correction (SSBC) method is applied, which has contributed to enhance the performance of precipitation simulation in the RMP [30]. This model has been successfully employed for numerous regional climate studies, especially for East Asian monsoon studies (e.g., [31-33]), and GCM downscaling studies for future climate projection [34] and added value identification [35].

2.2. Experimental Design. The model domain includes East Asia, India, the Western Pacific Ocean, and the northern part of Australia, as shown in Figure 1. Climatology analyses are conducted in Analysis Zone, while skill scores are tabulated for Northeast Asia. Intra-annual variation is analyzed over Korea (Figure 1). The number of grid points in Cartesian coordinates is 241 (west-east) by 198 (north-south) with nominal horizontal resolution of $50 \mathrm{~km}$. A 28 -level of terrainfollowing (sigma) vertical grid is used. The RMP experiments are conducted for current (1980-2000, hereafter 20C) and future (2040-2070, hereafter A1B) climates. Lateral boundary and sea surface temperature (SST) conditions are given from ECHAM5 simulation results at six-hour interval during the RMP simulation. Future change in radiative forcing follows the AlB emission scenario from the Special Report on Emission Scenarios (SRES) by the Intergovernmental Panel on Climate Change (IPCC) Fourth Assessment Report (AR4) [36]. For detailed description for the experimental setup, it is recommended to refer to Chang and Hong [37].

2.3. Evaluation Data. The modeled runoff is calculated by the NOAH LSM in the RMP. NOAH LSM tabulates surface runoff using Simple Water Balance model [38]. It defines surface runoff $(R)$ as a difference between throughfall rate of precipitation $(P)$ and infiltration $(I)$; that is, $R=P-$ $I$, where $I$ is decided as a function of soil moisture and texture [26]. The modeled runoff obtained from the RMP 20C experiment is compared with the regridded observational analysis dataset, namely, the International Satellite LandSurface Climatology Project, Initiative II (ISLSCP II), and the University of New Hampshire (UNH)/Global Runoff Data Centre (GRDC) Composite Monthly Runoff ([39]; available at http://daac.ornl.gov/cgi-bin/dsviewer.pl?ds_id=994; hereafter ISLSCP2). The ISLSCP2 data are generated based on a composite of satellite and station observation and are partly adjusted using the water balance model. This dataset contains monthly runoff analysis that has a spatial resolution of $0.5^{\circ} \times$ $0.5^{\circ}$ and covers global land region. It provides a detailed distribution of runoff. Since the ISLSCP2 partially covers the period of the $20 \mathrm{C}$ experiment, modeled monthly runoff 




FIGURE 1: Regional model domain and orography $(\mathrm{m})$. Primary, secondary inner, and innermost boxes indicate analysis zone excluding buffer zone, Northeast Asia, and Korea, respectively.

is evaluated for 1986-1995 period. The ISLSCP2 data are interpolated onto the RMP model grids for the evaluation.

\section{Evaluation of Current Climate Simulation}

It is generally agreed that downscaled surface variables such as precipitation and temperature should be comparable to observations of the same in order for the projected scenarios to be considered credible [40,41]. Since Chang and Hong [37] confirmed the RMP's ability in representing precipitation and near-surface temperature, we focus on evaluating surface runoff obtained from the RMP 20C experiment.

Figure 2 compares the seasonally averaged surface runoff obtained from the ISLSCP2 dataset and that simulated by the RMP. It is apparent that spatial distribution patterns of runoff are highly correlated with precipitation. For the present summer, June-July-August (JJA), two major strong runoff areas are observed; one is over the tropics, and the other is extended from southern China to Korea and Japan, which is related to the East Asia summer monsoon (EASM) precipitation (Figure 2(a)). The RMP captures EASM related runoff pattern well, while surplus runoff generally appears over the continental region, and deficient runoff appears over the tropics (Figures 2(b) and 2(c)). On the other hand, strong runoff regions in western side of India and Indochina are sufficiently reproduced by the RMP (Figure 2(b)). Throughout the model domain, there is general overestimation that is related to systematic wet bias due to excessively simulated precipitation of the RMP (see Figures 3(c)-3(d) in [37]). For winter, in December-January-February (DJF), the RMP adequately captures runoff pattern over Southern China, Korea, and Japan even though general overestimation appears. Here, DJF for a given year designates the period from December of that year to February of the following year. The pattern of tropical runoff is reproduced by the RMP, but its spatial deviation is much larger than that in the observation (Figure 2(f)). Despite the generally appearing wet bias in both summer
TABLE 1: Pattern correlation coefficient (PC) and root mean square error (RMSE, unit in $\mathrm{mm} / \mathrm{d}$ ) scores of simulated runoff from ECHAM5 run and RMP 20C experiment to the ISLSCP II reanalysis over Northeast Asia.

\begin{tabular}{lccc}
\hline Season & Model & PC & RMSE \\
\hline \multirow{2}{*}{ JJA } & RMP & 0.70 & 1.25 \\
& ECHAM5 & 0.43 & 0.98 \\
\hline \multirow{2}{*}{ DJF } & RMP & 0.74 & 1.19 \\
& ECHAM5 & 0.34 & 0.32 \\
\hline
\end{tabular}

and winter, the spatial pattern of the simulated runoff is well reproduced against the ISLSCP2 data.

Figure 3 shows runoff climatology fields as well as Figure 2, but they are obtained from ECHAM5 simulation results. Comparing to the RMP results in Figure 2, it is clear that ECHAM5 shows inferior performance to that of the RMP. For JJA, runoff is overestimated over Northeast Asia and concentrated runoff distribution along the west coast of India and Indochina Peninsula is not captured by the ECHAM5 (cf. Figures 2(a) and 3(a)). For DJF, runoff is underestimated especially for Southern China (cf. Figures 2(d) and 3(b)). Commonly, the ECHAM5-simulated runoff distribution is too smoothed to capture the observed climatology.

Table 1 summarizes the basic statistics for pattern correlation (PC) and root-mean square error (RMSE) of the runoff fields, obtained from ECHAM5 and RMP, against the ISLSCP2 dataset. To compute the skill scores, the ISLSCP2 data on half resolution latitude-longitude grid are interpolated onto the ECHAM5 and RMP model grids of approximately $180 \mathrm{~km}$ and $50 \mathrm{~km}$ resolutions, respectively. The RMSE scores are seemed to be slight better for the ECHAM5 than for the RMP; however, there is noticeable difference for PC scores between the RMP and ECHAM5. The PCs for RMP are above 0.7 in both JJA and DJF, while the PCs are below 0.5 for ECHAM5 results. This result indicates that the reliability of the RMP model results is much higher than that in the ECHAM5 result.

\section{Future Climate Changes}

To assess changes on runoff in the future climate, analyses of downscaled ECHAM5-A1B emission scenario by RMP are performed from 2040 to 2070. According to Chang and Hong [37], near-surface temperature shows a distinct increase in future climate of both JJA and DJF, while precipitation of future climatology is similar to the current climate over East Asia. Based on the results of Chang and Hong [37], analyses are focused on changes in water budget components and runoff pattern over Korea in this study. Future climate experiment $(\mathrm{AlB})$ is compared to those from the current climate experiment (20C), respectively.

To examine the impact of temperature change on runoff, differences in seasonal runoff between the $\mathrm{AlB}$ and $20 \mathrm{C}$ climatology are analyzed in Figure 4. There is remarkable increment of runoff over India and Indochina, while northwestern part of India, inland region of Southern China, and Korea show decreased runoff in summer (Figure 4(a)). 




(a) OBS, JJA



(b) RMP(20C), JJA

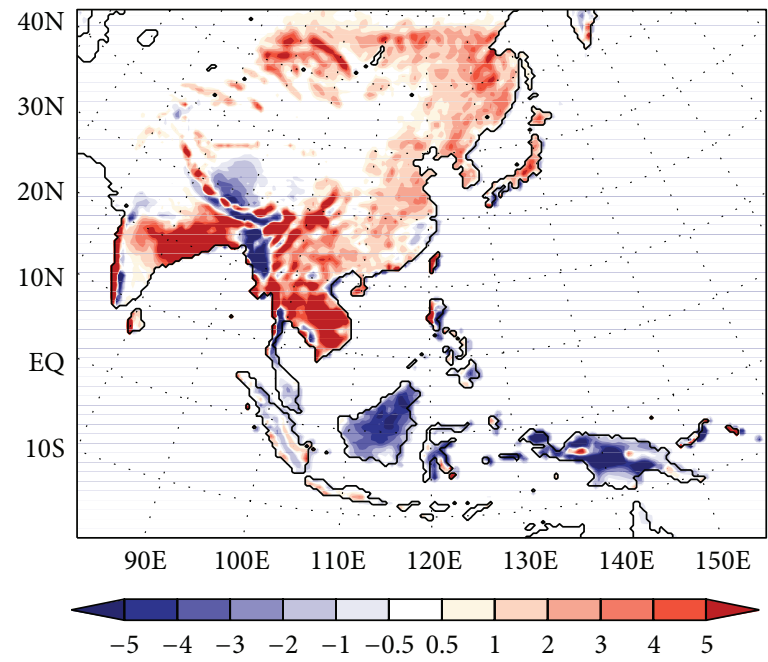

(c) RMP-OBS, JJA



(d) OBS, DJF



(e) RMP(20C), DJF



(f) RMP-OBS, DJF

FIGURE 2: Seasonally averaged runoff $\left(\mathrm{mm} \mathrm{d}^{-1}\right)$ obtained from (a) observation (ISLSCP2), (b) model 20C experiment, (c) and their difference (model minus observation) for JJA. (d) to (f) are same as (a) to (c) but for DJF. 




(a) ECHAM5, JJA


(b) ECHAM5, DJF

FIGURE 3: Seasonally averaged runoff $\left(\mathrm{mm} \mathrm{d}^{-1}\right)$ obtained from ECHAM5 simulation for (a) JJA and (b) DJF from 1986 to 1995.



(a) A1B-20C, JJA



(b) A1B-20C, DJF

FIGURE 4: Differences of seasonally averaged runoff $\left(\mathrm{mm} \mathrm{d}^{-1}\right)$ of the A1B run from the 20C run for (a) JJA and (b) DJF.

However, east coast of Southern China, south coast of Korea and Japan show increased runoff, which is related to EASM (Figure 4(a)). In DJF, continental region shows slight decrement of runoff, while runoff is increased in Korea and south coast of China (Figure 4(b)). Tropical region shows increased runoff in both JJA and DJF. Focusing on Korea, it is remarkable that change in opposite directions appears in JJA and DJF.

Figure 5 shows quantitative changes in main components of a water budget over Korea. In JJA, runoff and evaporation are increased by $9.1 \%$ and $5.9 \%$, respectively, while precipitation is decreased by $20.7 \%$. In DJF, runoff and precipitation are increased by $7.9 \%$ and $80.9 \%$ in the future climate, while evaporation is decreased by $1.6 \%$. Here, increment of runoff is distinctly influenced by large increment of precipitation. On the other hand, incremental percentage looks too large due to small absolute value of precipitation. These results indicate that the pattern of hydrological cycle is changed in the future climate.

Monthly variations of modeled water budget components: precipitation, evaporation, and runoff in current and future climate over Korea are shown in Figure 6. It is clearly shown that variation of runoff is highly correlated with variation of precipitation (cf. Figures 6(a) and 6(b)). There are remarkable intensified peak points in July of A1B experiment for both runoff and precipitation, while they are decreased in August and September compared to those of 20C experiment (Figures 6(a) and 6(b)). On the contrary, runoff in May 




20C



20C

A1B

(a) JJA

(b) DJF

FIGURE 5: Seasonally averaged runoff, precipitation, and evaporation $\left(\mathrm{mm} \mathrm{d}^{-1}\right)$ for (a) JJA and (b) DJF over land of Korea.



(a) Runoff

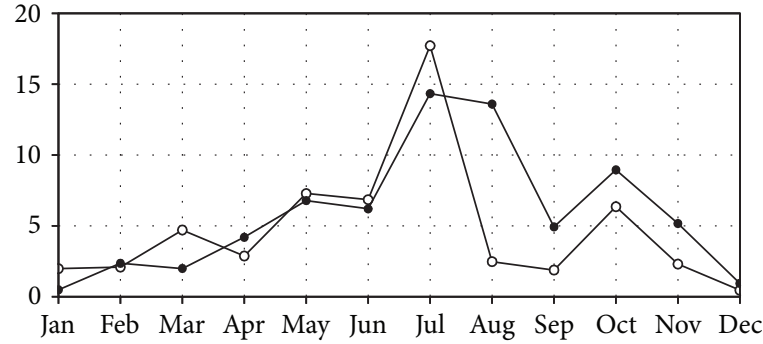

(b) Precipitation



(c) Evaporation

FIGURE 6: Monthly variations of simulated (a) runoff, (b) precipitation, and (c) evaporation ( $\mathrm{mm} \mathrm{d}^{-1}$ ) obtained from 20C (closed circle) and A1B (open circle) experiments, over land of Korea (innermost box of Figure 1).

and June is intensified (Figures 6(a) and 6(b)). In the future climate, evaporation is generally increased in May to August (Figure 6(c)), and it is a natural outcome of temperature rising (see Figures 7 (c)-7(d) in [37]). These imply that temperature warming has a significant influence on intra-annual distribution of runoff. Moreover, it increases variability of runoff in summer and shows strengthened possibility of extreme occurrence. Since these results are derived from $50 \mathrm{~km}$ resolution simulation and quantities are area-averaged over Korea, they cannot provide accurate quantitative value of change. However, through these comparative analyses of current and future climatology, it is able to access relative changing patterns of water budget components due to climate change.

\section{Summary and Concluding Remarks}

This study investigated potential future changes in the climate over Korea with focus on surface runoff and its intra-annual variation. For this purpose, current climate and future climate projection scenario were dynamically downscaled using 
the GRIMs-RMP. The A1B scenario driven by ECHAM5 simulation provided large-scale forcing to the RMP simulations, which were configured with an approximately $50 \mathrm{~km}$ grid over the Asian and tropical region. Simulations were conducted for the current (1980-2000) and future (20402070) climates.

As a prerequisite for the assessment of future runoff change, modeled surface runoff obtained from the current climate simulation was evaluated by comparing with observation-based reanalysis dataset, namely, ISLSCP2. Since reproducibility of the RMP for precipitation and near-surface temperature is confirmed in Chang and Hong [37], we focused on analyzing simulated surface runoff. The evaluation results indicated that the RMP is able to reproduce major characteristics of climatology of runoff distribution, even though there is wet bias.

To identify potential future climate change, the A1B scenario of IPCC AR4 generated by ECHAM5 was downscaled and compared with the current climate. Here, we concentrated on changes of water budget components including runoff, precipitation, and evaporation and their intra-annual variation over the Korean region. Increasing temperature trends in future climate have shown that they have significant impacts on the intra-annual runoff variation. The variability of runoff is increased in summer, and moreover, strengthened possibility of extreme occurrence is detected in the future climate.

The result of this study reflects that global warming affects local hydrological cycle by changing major water budget components. Considering some fundamental limitations of this study-uncertainties of global and regional climate model, low horizontal resolution of the model, consideration of only one type of future climate scenario assuming stabilization of warming in the future without overshooting, and focusing on the Korean region only, it is hard to assure that future runoff change would occur as it did in our study. Nevertheless, this study adduces that the importance of runoff should not be overlooked in the regional climate studies. Runoff is one of the major input components of river discharge, and consequently, rivers flow into the ocean reducing salinity and changing sea-surface temperature. Naturally, varying ocean conditions influence the atmosphere. The coupling of ocean and atmospheric model in regional scale is in infancy stage in regional climate research community, and the interaction of heat fluxes is a major concern at the interface of ocean and atmosphere. It is emphasized that the loading of full hydrological cycling processes including runoff and river discharging should be the goal for the next-generation regional climate modeling.

\section{Conflict of Interests}

The authors declare that there is no conflict of interests regarding the publication of this paper.

\section{Acknowledgments}

The authors thank anonymous reviewer(s) for valuable comments and suggestions to improve the quality of this paper.
They also thank Ms. Hyun-Soo Kim in the University of Pittsburgh for helping the authors to revise the paper. This work was funded by the Korea Institute of Science and Technology Information (KISTI) under Grant no. K-14-L01C04-S01. The use of a computing system from the KISTI (Project no. KSC-2013-G3-003) is also greatly appreciated.

\section{References}

[1] N. W. Arnell, "Climate change and global water resources: SRES emissions and socio-economic scenarios," Global Environmental Change, vol. 14, no. 1, pp. 31-52, 2004.

[2] R. W. Higgins, A. Leetmaa, Y. Xue, and A. Barnston, "Dominant factors influencing the seasonal predictability of U.S. precification and surface air temperature," Journal of Climate, vol. 13, no. 22, pp. 3994-4017, 2000.

[3] V. Mishra, K. A. Cherkauer, and S. Shukla, "Assessment of drought due to historic climate variability and projected future climate change in the Midwestern United States," Journal of Hydrometeorology, vol. 11, no. 1, pp. 46-68, 2010.

[4] C.-Y. Xu, "Climate change and hydrologic models: a review of existing gaps and recent research developments," Water Resources Management, vol. 13, no. 5, pp. 369-382, 1999.

[5] G. E. Liston and Y. C. Sud, "Evaluating GCM land surface hydrology parameterizations by computing river discharges using a runoff routing model: application to the Mississippi basin," Journal of Applied Meteorology, vol. 33, no. 3, pp. 394405, 1994.

[6] D. M. Wolock and G. J. McCabe, "Estimates of runoff using water-balance and atmospheric general circulation models," Journal of the American Water Resources Association, vol. 35, no. 6, pp. 1341-1350, 1999.

[7] K. Fraedrich, F. Sielmann, D. Cai, L. Zhang, and X. Zhu, "Validation of an ideal rainfall-runoff chain in a GCM environment," Water Resources Management, 2014.

[8] N. S. Christensen and D. P. Lettenmaier, "A multimodel ensemble approach to assessment of climate change impacts on the hydrology and water resources of the Colorado River Basin," Hydrology and Earth System Sciences, vol. 11, no. 4, pp. 1417-1434, 2007.

[9] K. Hayhoe, C. P. Wake, T. G. Huntington et al., "Past and future changes in climate and hydrological indicators in the US Northeast," Climate Dynamics, vol. 28, no. 4, pp. 381-407, 2007.

[10] M. M. Elsner, L. Cuo, N. Voisin et al., "Implications of 21st century climate change for the hydrology of Washington State," Climatic Change, vol. 102, no. 1-2, pp. 225-260, 2010.

[11] E. Sanchez-Gomez, S. Somot, and A. Mariotti, "Future changes in the Mediterranean water budget projected by an ensemble of regional climate models," Geophysical Research Letters, vol. 36, no. 21, Article ID L21401, 2009.

[12] E. Kjellström and P. Lind, "Changes in the water budget in the Baltic Sea drainage basin in future warmer climates as simulated by the regional climate model RCA3," Boreal Environment Research, vol. 14, no. 1, pp. 114-124, 2009.

[13] E. P. Salathé Jr., "Comparison of various precipitation downscaling methods for the simulation of streamflow in a rainshadow river basin," International Journal of Climatology, vol. 23, no. 8, pp. 887-901, 2003.

[14] L. R. Leung, Y. Qian, X. Bian, W. M. Washington, J. Han, and J. O. Roads, "Mid-century ensemble regional climate change 
scenarios for the Western United States," Climatic Change, vol. 62, no. 1-3, pp. 75-113, 2004.

[15] E. P. Salathé Jr., R. Steed, C. F. Mass, and P. H. Zahn, "A high-resolution climate model for the U.S. Pacific Northwest: mesoscale feedbacks and local responses to climate change," Journal of Climate, vol. 21, no. 21, pp. 5708-5726, 2008.

[16] S.-Y. Hong, N.-K. Moon, K.-S. S. Lim, and J.-W. Kim, "Future climate change scenarios over Korea using a multi-nested downscaling system: a pilot study," Asia-Pacific Journal of Atmospheric Sciences, vol. 46, no. 4, pp. 425-435, 2010.

[17] S.-Y. Hong and M. Kanamitsu, "Dynamical downscaling: Fundamental issues from an NWP point of view and recommendations," Asia-Pacific Journal of Atmospheric Sciences, vol. 50, no. 1, pp. 83-104, 2014.

[18] Y. Shi, X. Gao, D. Zhang, and F. Giorgi, "Climate change over the Yarlung Zangbo-Brahmaputra River Basin in the 21st century as simulated by a high resolution regional climate model," Quaternary International, vol. 244, no. 2, pp. 159-168, 2011.

[19] S.-Y. Hong, H. Park, H.-B. Cheong et al., "The global/regional integrated model system (GRIMs)," Asia-Pacific Journal of Atmospheric Sciences, vol. 49, no. 2, pp. 219-243, 2013.

[20] E. Roeckner, G. Bäuml, L. Bonaventura et al., "The atmospheric general circulation model ECHAM5. Part I: model description," Tech. Rep. 349, Max Planck Institute for Meteorology, Hamburg, Germany, 2003.

[21] H.-M. H. Juang and M. Kanamitsu, "The NMC nested regional spectral model," Monthly Weather Review, vol. 122, no. 1, pp. 326, 1994.

[22] H.-M. H. Juang, S.-Y. Hong, and M. Kanamitsu, "The NCEP regional spectral model: An update," Bulletin of the American Meteorological Society, vol. 78, no. 10, pp. 2125-2143, 1997.

[23] S.-Y. Hong and H.-L. Pan, "Convective trigger function for a mass-flux cumulus parameterization scheme," Monthly Weather Review, vol. 126, no. 10, pp. 2599-2620, 1998.

[24] S.-Y. Hong, H.-M. H. Juang, and Q. Zhao, "Implementation of prognostic cloud scheme for a regional spectral model," Monthly Weather Review, vol. 126, no. 10, pp. 2621-2639, 1998.

[25] S.-Y. Hong, Y. Noh, and J. Dudhia, "A new vertical diffusion package with an explicit treatment of entrainment processes," Monthly Weather Review, vol. 134, no. 9, pp. 2318-2341, 2006.

[26] F. Chen and J. Dudhia, "Coupling and advanced land surfacehydrology model with the Penn State-NCAR MM5 modeling system. Part I. Model implementation and sensitivity," Monthly Weather Review, vol. 129, no. 4, pp. 569-585, 2001.

[27] M. B. Ek, K. E. Mitchell, Y. Lin et al., "Implementation of Noah land surface model advances in the National Centers for Environmental Prediction operational mesoscale Eta model," Journal of Geophysical Research, vol. 108, no. 22, pp. 1-16, 2003.

[28] M.-D. Chou, "A solar radiation model for use in climate studies," Journal of the Atmospheric Sciences, vol. 49, no. 9, pp. 762-772, 1992.

[29] M.-D. Chou, K.-T. Lee, S.-C. Tsay, and Q. Fu, "Parameterization for cloud longwave scattering for use in atmospheric models," Journal of Climate, vol. 12, no. 1, pp. 159-169, 1999.

[30] S.-Y. Hong and E.-C. Chang, "Spectral nudging sensitivity experiments in a regional climate model," Asia-Pacific Journal of Atmospheric Sciences, vol. 48, no. 4, pp. 345-355, 2012.

[31] H.-S. Kang and S.-Y. Hong, "An assessment of the land surface parameters on the simulated regional climate circulations: the 1997 and 1998 east Asian summer monsoon cases," Journal of Geophysical Research, vol. 113, no. D15, artcile D14121, 2008.
[32] M. Kanamitsu, K. Yoshimura, Y.-B. Yhang, and S.-Y. Hong, "Errors of interannual variability and trend in dynamical downscaling of reanalysis," Journal of Geophysical Research D: Atmospheres, vol. 115, no. 17, Article ID D17115, 2010.

[33] M.-S. Koo and S.-Y. Hong, " Diurnal variations of simulated precipitation over East Asia in two regional climate models," Journal of Geophysical Research, vol. 115, no. D5, pp. 10-1029, 2010.

[34] J.-W. Lee, S.-Y. Hong, E.-C. Chang, M.-S. Suh, and H.-S. Kang, "Assessment of future climate change over East Asia due to the RCP scenarios downscaled by GRIMs-RMP," Climate Dynamics, vol. 42, no. 3-4, pp. 733-747, 2014.

[35] J.-W. Lee and S.-Y. Hong, "Potential for added value to downscaled climate extremes over Korea by increased resolution of a regional climate model," Theoretical and Applied Climatology, vol. 117, no. 3-4, pp. 667-677, 2013.

[36] N. Nakicenovic, J. Alcamo, G. Davis et al., Special Report on Emissions Scenarios, Cambridge University Press, Cambridge, UK, 2000, Working Group III, Intergovernmental Panel on Climate Change (IPCC), http://www.grida.no/climate/ipcc/ emission/index.htm.

[37] E.-C. Chang and S.-Y. Hong, "Projected climate change scenario over East Asia by a regional spectral model," Journal of Korean Earth Science Society, vol. 32, no. 7, pp. 770-783, 2011.

[38] J. C. Schaake, V. I. Koren, Q.-Y. Duan, K. Mitchell, and F. Chen, "Simple water balance model (SWB) for estimating runoff at different spatial and temporal scales," Journal of Geophysical Research, vol. 101, no. 3, pp. 7461-7475, 1996.

[39] B. Fekete, T. Maurer, and C. J. Vörösmarty, "ISLSCP II UNH/GRDC composite monthly runoff," in ISLSCP Initiative II Collection. Data Set, F. G. Hall, G. Collatz, B. Meeson, S. Los, E. Brown de Colstoun, and D. Landis, Eds., Oak Ridge National Laboratory Distributed Active Archive Center, Oak Ridge, Tenn, USA, 2011, http://daac.ornl.gov/.

[40] X.-Z. Liang, L. Li, K. E. Kunkel, M. Ting, and J. X. L. Wang, "Regional climate model simulation of U.S. precipitation during 1982-2002. Part I: annual cycle," Journal of Climate, vol. 17, pp. 3510-3529, 2004.

[41] Y. Wang, L. R. Leung, J. L. McGregor et al., "Regional climate modeling: progress, challenges, and prospects," Journal of the Meteorological Society of Japan, vol. 82, no. 6, pp. 1599-1628, 2004. 

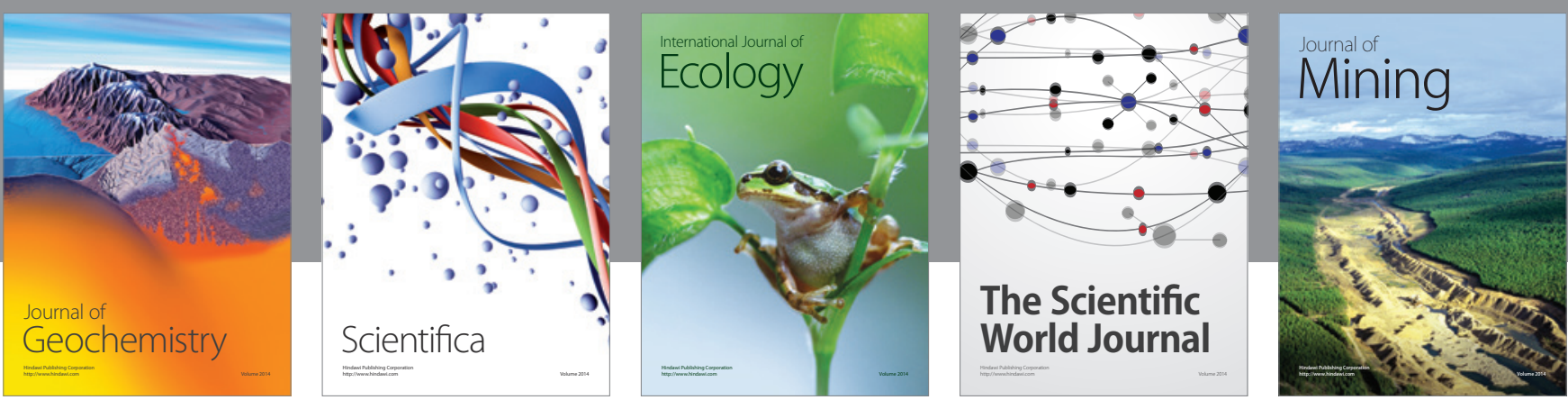

The Scientific World Journal
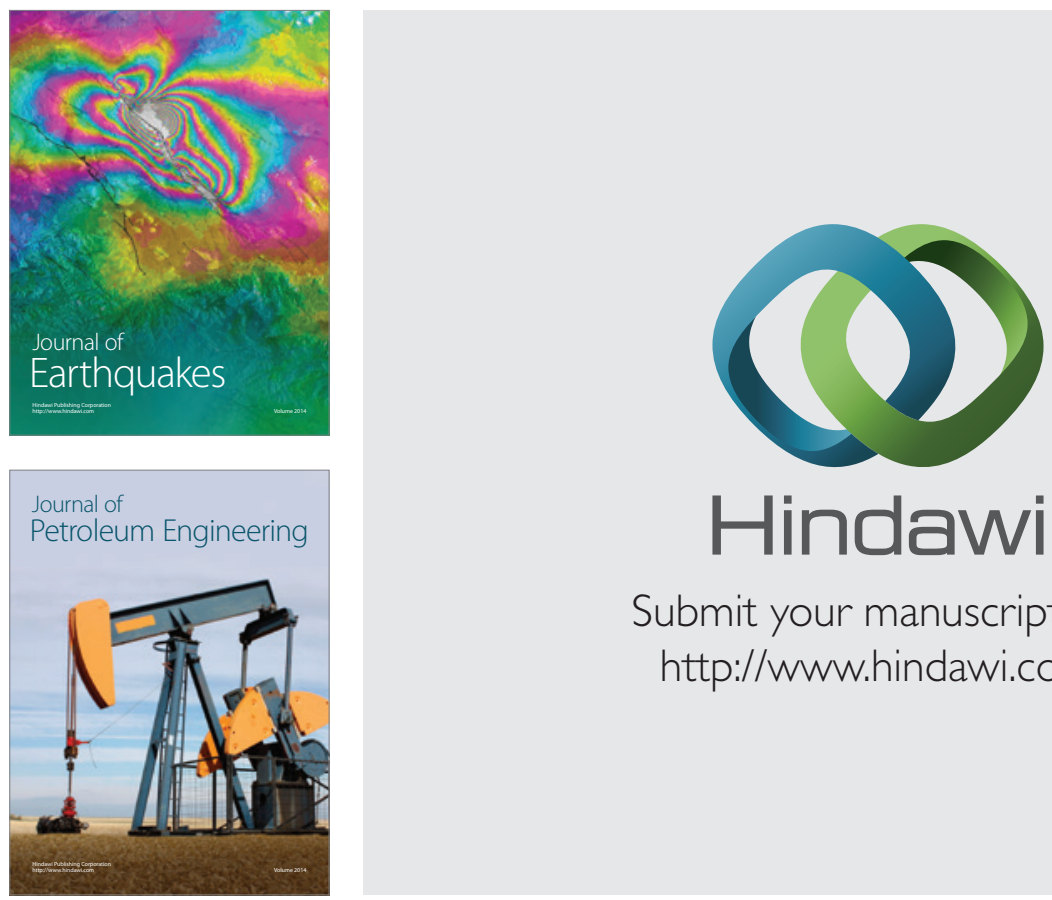



Submit your manuscripts at

http://www.hindawi.com
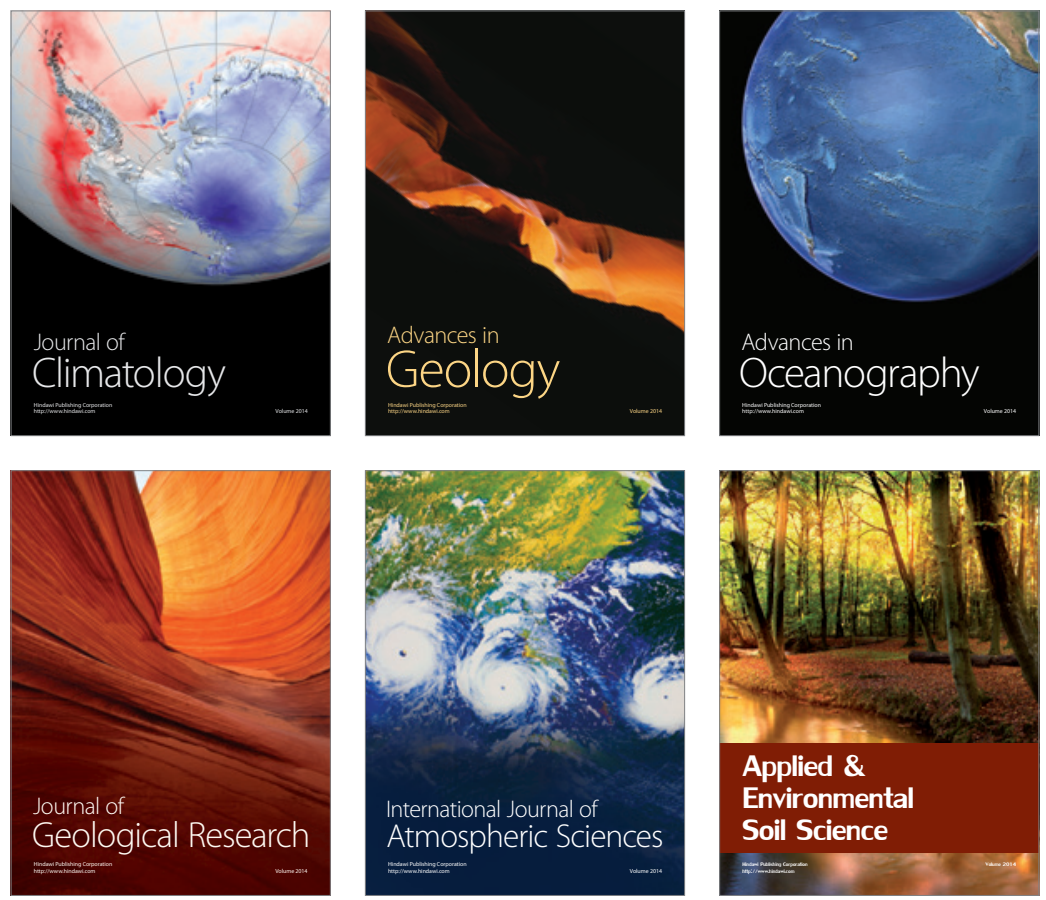
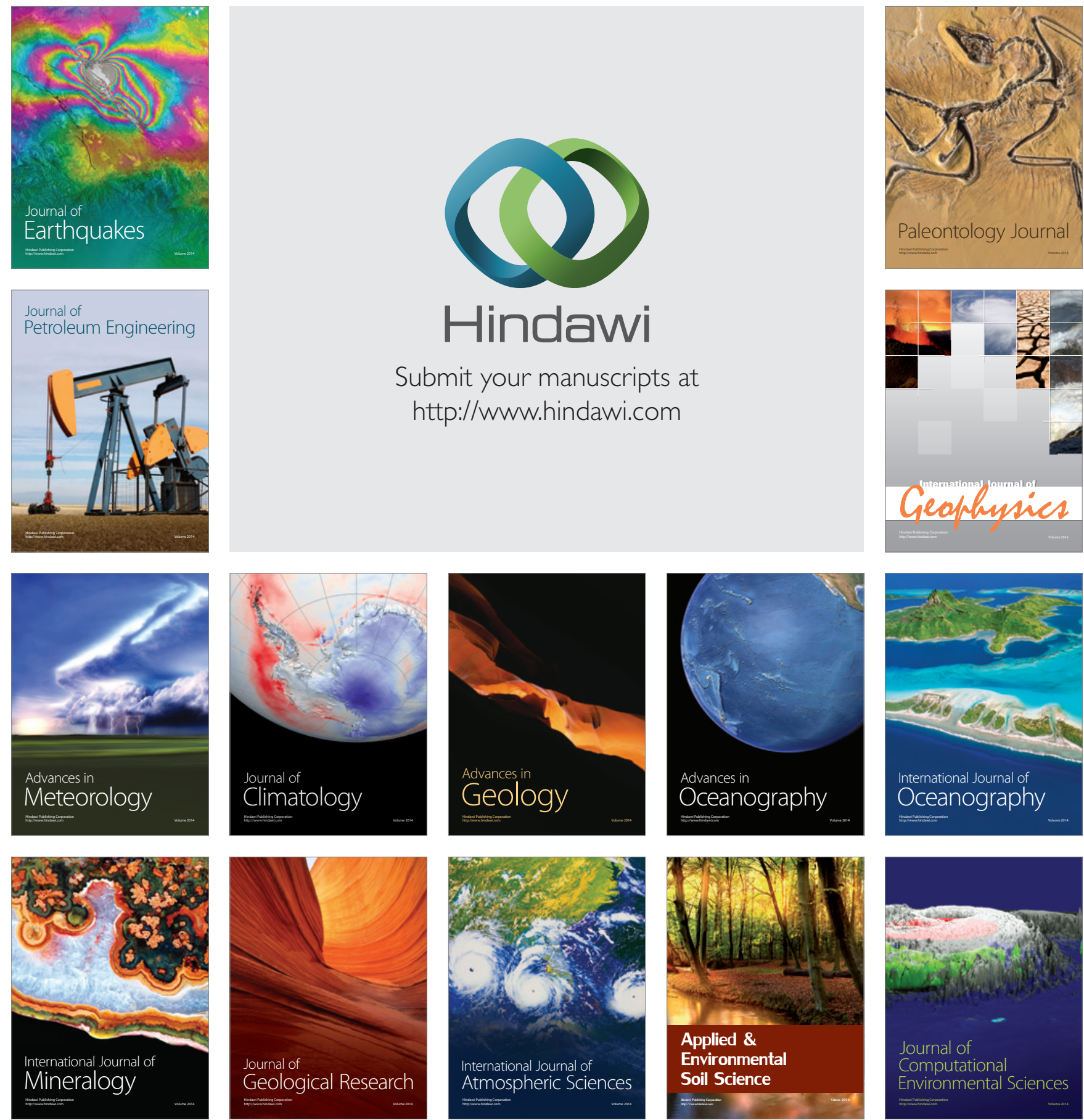